\title{
THE CENTRAL PATH OF THE LIGHT REFLEX VIA THE SYMPATHETIC NERVE IN THE CAT
}

\author{
Hiromasa OKada, Osamu NaKano, Kyoko OKamoto, \\ Kimihiro NAKAYAMA AND Isamu Nisida* \\ Department of Physiology, Tottori University School of Medicine, Yonago
}

The afferent path to the pupillo-constrictory centers from the retina was studied by numerous authors and clarified considerably in detail, whereas the optic afferent path to the cilio-spinal centers in the spinal cord remained entirely obscure. Some authors doubted whether the ocular sympathetic fibers exerted for the development of the pupillary light reflex for the reason that the pupillary movements provoked by lighting the retina were scarcely recognized after the severance of the ocular parasympathetic nerves. It was however unequivocally demonstrated, in our recent reports ${ }^{8,9)}$, that the pupillary light reflex was mediated not only through the parasympathetic nerve but also through the sympathetic nerve the activity of which was inhibited in the light reflex.

The following experiment was designed to decide the central path to the cilio-spinal centers from the retina by observing the response in the activity of the ocular sympathetic nerve to lighting the retina after various lesions of the brain stem and cutting the optic tract. From the obtained results, a new schema concerned with the light reflex path was induced.

\section{METHODS}

The experiments were performed on cats weighing 2-4 kg., anesthetized with urethane $(0.25-0.5 \mathrm{~g} / \mathrm{kg}$.). The animals were occasionally decorticated. The efferent impulses in the long ciliary nerve were used as an index of the activity of the cilio-spinal centers. The unilateral eyeball was enucleated and then the long ciliary nerve was dissected from the surrounding tissues. The efferent impulses from its nerve were recorded by means of a method similar to that in the previous $\operatorname{article}^{9)}$.

The contralateral eye was illuminated with light of 1000-1500 lux for the purpose of ascertaining the reflex response of the long ciliary nerve to lighting the retina before and after a partial destruction of the brain stem through various levels as well as the severance of the optic tract.

The midbrain was exposed by means of the method described in the previous $\left.\operatorname{article}^{\tau}\right)$, taking great care to prevent hemorrhage from the sinuses in the bone

Received for publication May 20, 1960.

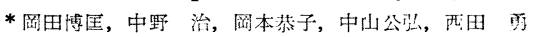


and from vessels passing from the dura to the bone after removing the parietal and tempolar bones and exposing the cerebral hemispherale Then the neural structure of the midbrain was cut sagittally at the midline with a small knife made from the razor blade. The severance of the optic tract was intracranially performed, pushing up the brain with a thin metal spatula inserted between the basal bone and the brain. A partial destruction or hemisection of the pons and medulla oblongata was performed after removing the dorsal part of the occipital bone and the cerebellum and exposing freely the dorsal surface of the pons and medulla oblongata. After the experiments traces of the transection were confirmed histologically.

\section{RESULTS}

1. A partial decussation in the optic chiasma of the afferent path inhibiting the activity of the cilio-spinal centers; This experiment was undertaken for the purpose of ascertaining whether the afferent path inhibiting the activity of the cilio-spinal centers formed a partial decussation in the optic chiasma as seen in the afferent path concerning the visual sensation and running to the oculomotor nuclei in the midbrain.

After cutting the left optic tract intracranially, the efferent impulses in the left long ciliary nerve were still inhibited by lighting the contralateral eye as illustrated in FIG. $1 \mathrm{~B}_{1}$. In other cases in which the right optic tract was cut and the left was intact, similar inhibition of the efferent impulses in the left long ciliary nerve was evoked by lighting the right eye (FIG. $3 \mathrm{~B}_{1}$ ), while such an inhibition was abolished by cutting the bilateral optic tracts. Reflex inhibition described above was irrespective of the presence of the cerebral cortex.

Although the direct pupillary light reflex was not studied because the enucleation of the unilateral eyeball was required for recording the efferent impulses in the long ciliary nerve, similar inhibition to that observed in the consensual light reflex might probably be provoked.

From the results described above, it is obvious that the afferent impulses from the retina of the unilateral eye, inhibiting the activity of the cilio-spinal centers, run to the brain stem through bilateral optic tracts after a partial crossing in the optic chiasma. Furthermore, from the facts that the reflex inhibition of the activity in the long ciliary nerve is able to evoke not only through the homolateral optic tract but also through the contralateral one, the optic afferent path via the unilateral optic tract seems to reach the bilateral cilio-spinal centers after a partial decussation at some part of the brain stem or spinal cord. This assumption is clarified in the following experiments.

2. The inhibitory path from the unilateral optic tract to the contralateral cilio-spinal center; After confirming the presence of the inhibitory response in 
the left long ciliary nerve to lighting the retina after cutting the left optic tract (FIG. $1 \mathrm{~B}_{1}$ ), transection of the left half of the pons was performed. In such preparations the inhibitory response in the long ciliary nerve to lighting the retina could still be recognized as illustrated in FIG. $1 \mathrm{~B}_{2}$. Furthermore, in other cases, the ipsilateral hemisection of the medulla oblongata at the level of the obex adding the severance of the left optic tract did not abolish such an inhibition in the left long ciliary nerve (FIG. $1 \mathrm{~B}_{3}$ ).

This observation indicates that some of the afferent impulses which enter

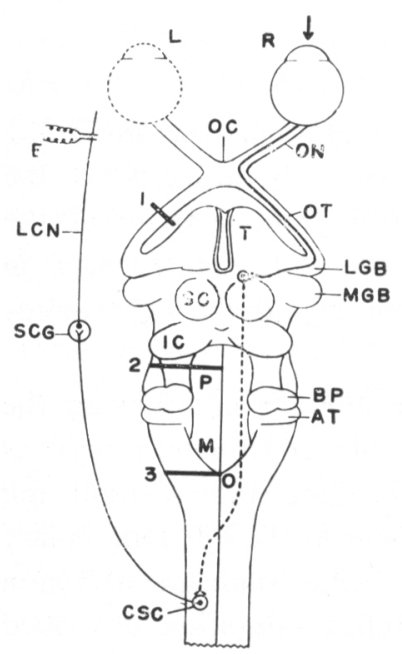

A

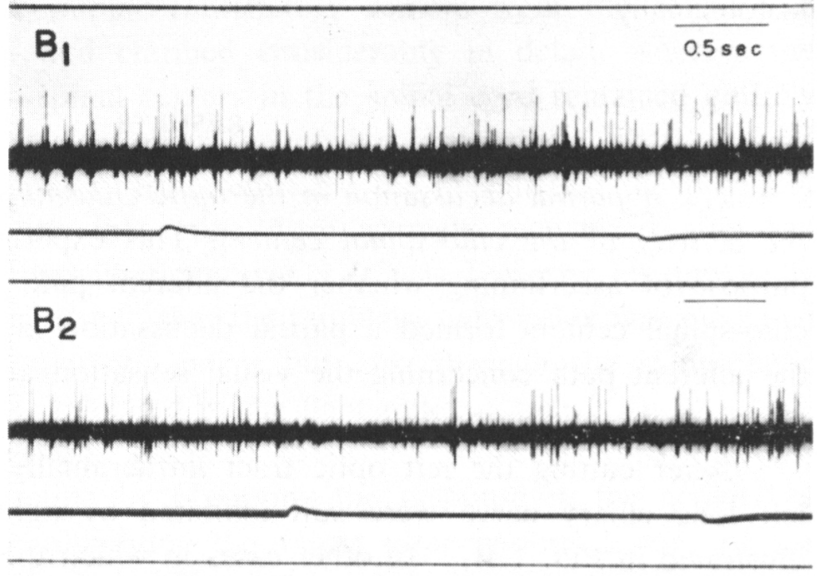

$\mathrm{B}_{3}$

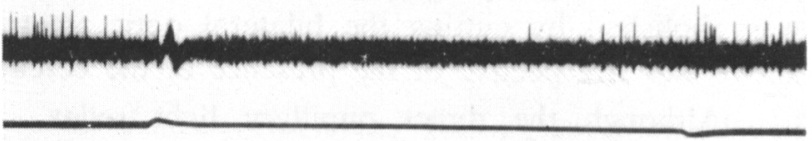

B

FIG. 1 A. The inhibitory path from the unilateral optic tract to the contralateral cilio-spinal center. ON : optic nerve, OC: optic chiasma, OT: optic tract, T: thalamus, PRE: pretectal region, LGB: lateral geniculate body, MGB: medial geniculate body, SC: superior colliculus, IC: inferior colliculus, P: pons, $\mathrm{M}$ : medulla oblongata, $\mathrm{O}$ : obex, BP: brachium pontis, AT: acustic tubercle, CSC: cilio-spinal center, CSN : cervical sympathetic nerve, SCG: superior cervical ganglion, LCN: long ciliary nerve, E: recording electrode, L: left eye, R: right eye. Dotted line indicates the inhibitory path to the cilio-spinal center. (Description for following figures is the same).

1: severance of the left optic tract, 2: transection of the left half of the pons, 3 : transection of the left half of the medulla oblongata.

FIG. 1 B. Response in the activity of the long ciliary nerve to lighting the retina after various lesions. Action potentials : led from the left long ciliary nerve. The right eye was illuminated. Lower line signaled by phototube: upwards indicates light on, downwards light off. $\mathbf{B}_{1}$ : after cutting the left optic tract, $\mathbf{B}_{2}$ : after additional transection of the left half of the pons, $B_{3}$ : after transection of the left half of the medulla oblongata at the level of obex. 
into the brain stem through the unilateral optic tract descend the ipsilateral midbrain, pons and medulla oblongata. Then they transit to the contralateral side of the spinal cord and reach the cilio-spinal center on its side as illustrated by the dotted line in FIG. $1 \mathrm{~A}$.

Further experiment was attempted to clarify whether the pathway of the afferent impulses described above decussated also in the midbrain or not. The inhibitory response in the left long ciliary nerve to lighting the right eye was still obtained after the right pontile hemisection at the level of the cranial end of the pons in addition to cutting the left optic tract (FIG. $2 \mathrm{~B}_{1}$ ). Such a response was however abolished by additional mid-sagittal section of the midbrain (FIG. $2 \mathrm{~B}_{3}$ ). Therefore, it may be stated that the afferent fibers, which enter into the brain stem through the unilateral optic tract, reach the contralateral cilio-spinal center after a partial decussation in the midbrain besides the spinal cord as illustrated by the dotted line in FIG. $2 \mathrm{~A}$.

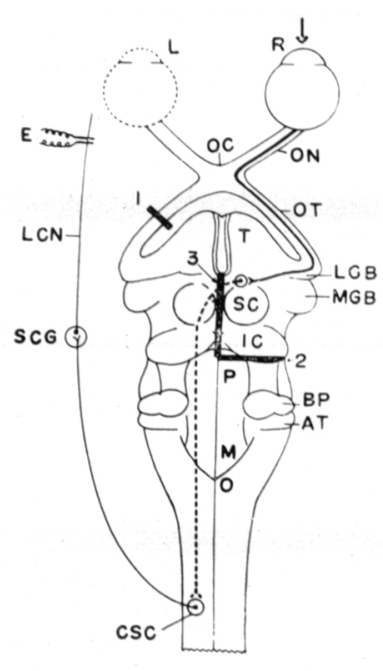

A
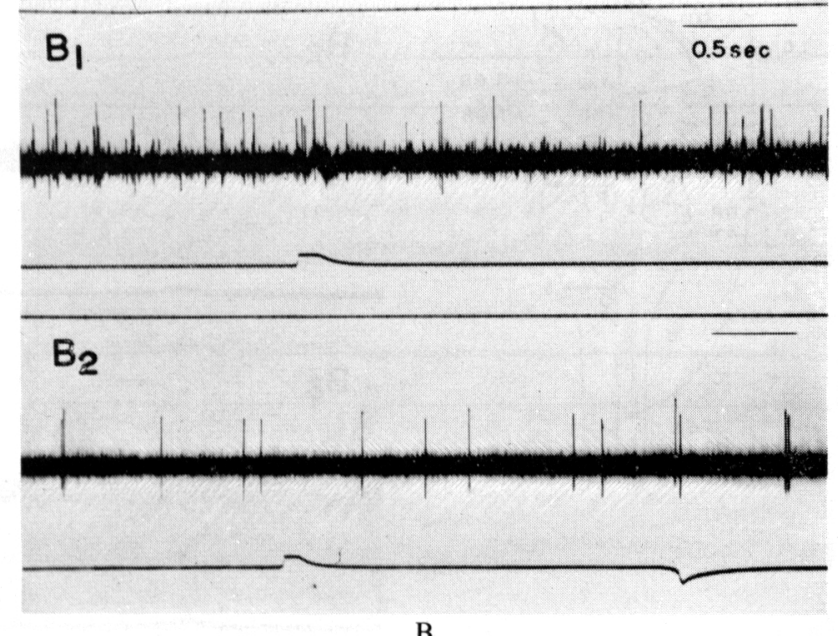

B

FIG. 2 A. The inhibitory path from the unilateral optic tract to the contralateral cilio-spinal center. 1: severance of the left optic tract, 2: transection of the right half of the pons, 3: mid-sagittal section of the midbrain.

FIG. 2 B. Response in the activity of the long ciliary nerve to lighting the retina after various lesions. Action potentials: led from the left long ciliary nerve. The right eye was illuminated. $\mathbf{B}_{1}$ : after cutting the left optic tract and transection of the right half of the pons, $\mathbf{B}_{2}$ : after additional mid-sagittal section of the midbrain.

3. The inhibitory path from the unilateral optic tract to the ipsilateral cilio-spinal center; After cutting the right optic tract intracranially, the efferent impulses in the left long ciliary nerve were still inhibited by lighting the right eye 
as illustrated in FIg. $3 \mathrm{~B}_{1}$. Additional transection of the right half of the pons as well as of the medulla oblongata at the level of the obex did not abolish such reflex inhibition in the long ciliary nerve (FIG. $3 \mathrm{~B}_{2} \mathrm{~B}_{3}$ ).

This result gives evidence that the afferent impulses, which enter into the brain stem through the unilateral optic tract, descend the ipsilateral midbrain, pons, medulla oblongata and spinal cord, and they inhibit the activity of the homolateral cilio-spinal center discharging the spontaneous impulses ${ }^{9)}$. The dotted line in FIG. $3 \mathrm{~A}$ shows such a path.

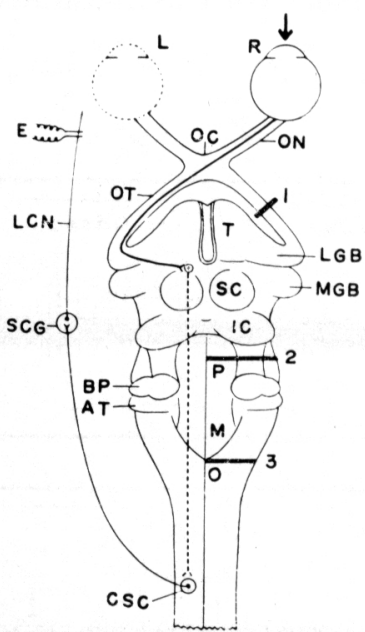

A

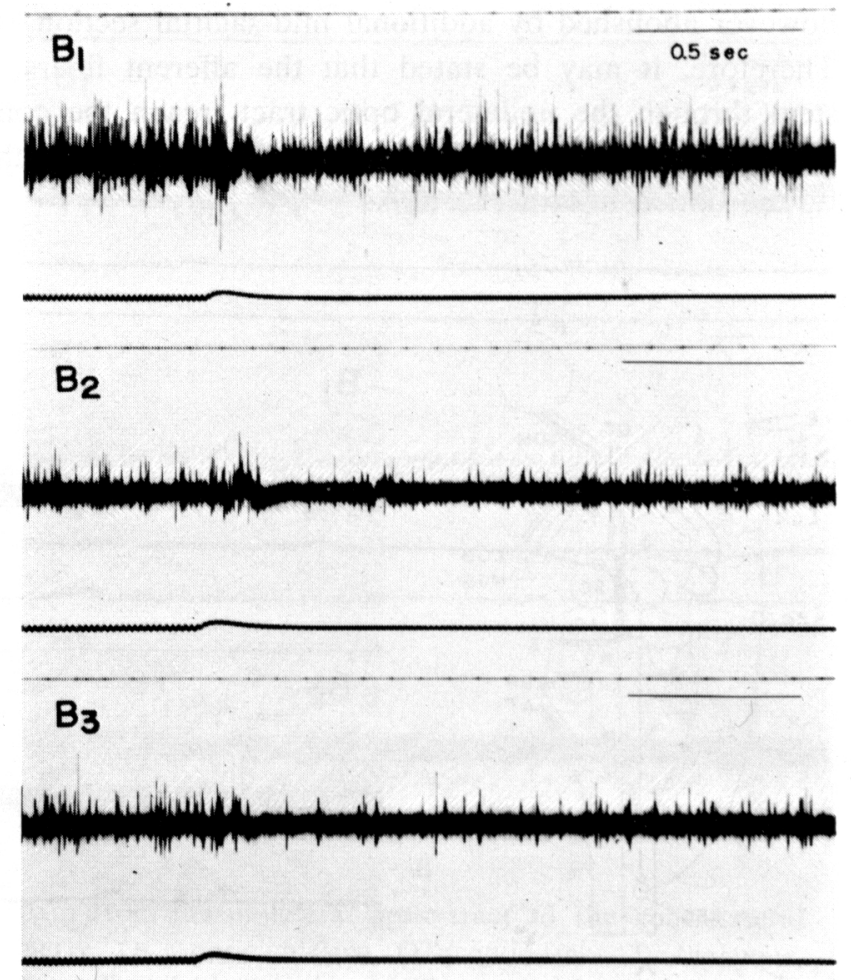

B

FIG. 3 A. The inhibitory path from the unilateral optic tract to the ipsilateral cilio-spinal center. 1: severance of the right optic tract, 2 : transection of the right half of the pons, 3: transection of the right half of the medulla oblongata through the obex.

FIG. 3 B. Response in the activity of the long ciliary nerve to lighting the retina after various lesions. $\mathbf{B}_{1}$ : after cutting the right optic tract, $\mathbf{B}_{2}$ : after additional transection of the right half of the pons, $\mathbf{B}_{3}$ : after transection of the right half of the medulla through the obex.

Furthermore, the following experiment shows that there is another path besides the path described above, passing from the unilateral optic tract to the 
ipsilateral cilio-spinal center.

After ascertaining the presence of the inhibitory response in the left long ciliary nerve to lighting the right eye after severing the right optic tract (FIG. $4 \mathrm{~B}_{1}$ ), transection of the left half of the pons through the cranial end was performed for the purpose of interrupting the inhibitory path illustrated by the dotted line in FIG. 3 A. Such an operation did not abolish reflex inhibition of the activity in the left long ciliary nerve to lighting the retina (FIG. $4 \mathrm{~B}_{2}$ ), although its degree diminished than that prior to the pontile hemisection. However, reflex inhibition in the long ciliary nerve was abolished by transecting additionally the right half of the medulla oblongata through the obex as shown in FIG. $4 \mathrm{~B}_{3}$. It is considered, accordingly, that there is a path illustrated by the dotted line in FIG. 4 A.

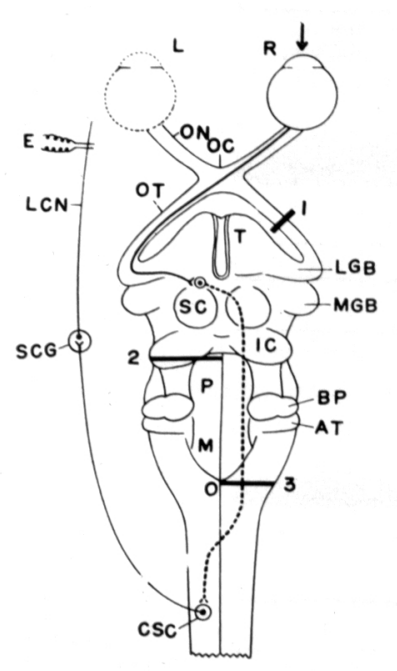

A
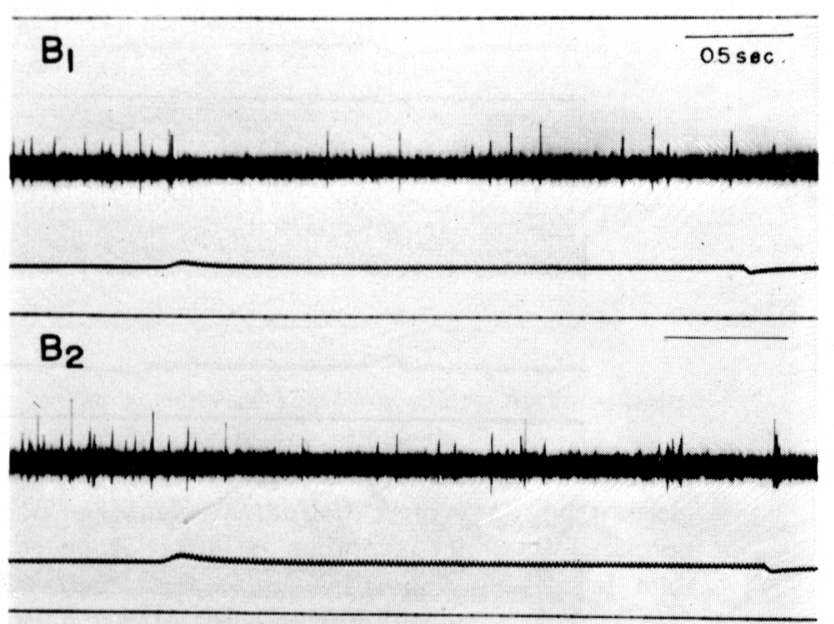

$\mathrm{B}_{3}$

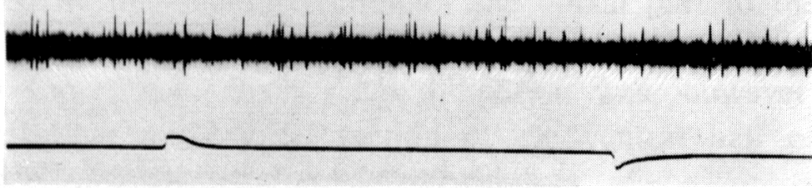

B

FIG. 4 A. The inhibitory path from the unilateral optic tract to the ipsilateral ciliospinal center. 1: severance of the right optic tract, 2: transection of the left half of the pons, 3: transection of the right half of the medulla oblongata.

FIG. 4 B. Response in the activity of the long ciliary nerve after various lesions. Action potentials: led from the left long ciliary nerve. The right eye was illuminated. $\mathrm{B}_{1}$ : after cutting the right optic tract, $\mathbf{B}_{2}$ : after additional transection of the left half of the pons, $\mathbf{B}_{3}$ : after additional transection of the right half of the medulla oblongata.

4. Decussation of the light reflex afferent path in the midbrain; This experiment was performed for the purpose of ascertaining whether the light reflex fibers 
running to the cilio-spinal centers crossed at the ventral or dorsal part to the Sylvian aqueduct in the midbrain.

In this study, the section of the left optic tract and transection of the right half of the upper pons were previously performed in order to interrupt other possible pathways except a path, passing from the left optic tract to the contralateral cilio-spinal center after decussation in the midbrain as illustrated by the dotted line in Fig. 2 A. Subsequently, on such preparations two sorts of experiments were performed: in one series of study, mid-sagittal section of the midbrain was placed on the dorsal part of the Sylvian aqueduct and then its ventral part, while in the other, such sections were made oppositely.

Reflex inhibition in the left long ciliary nerve to lighting the retina after cutting the left optic tract and sectioning transversely the right half of the pons

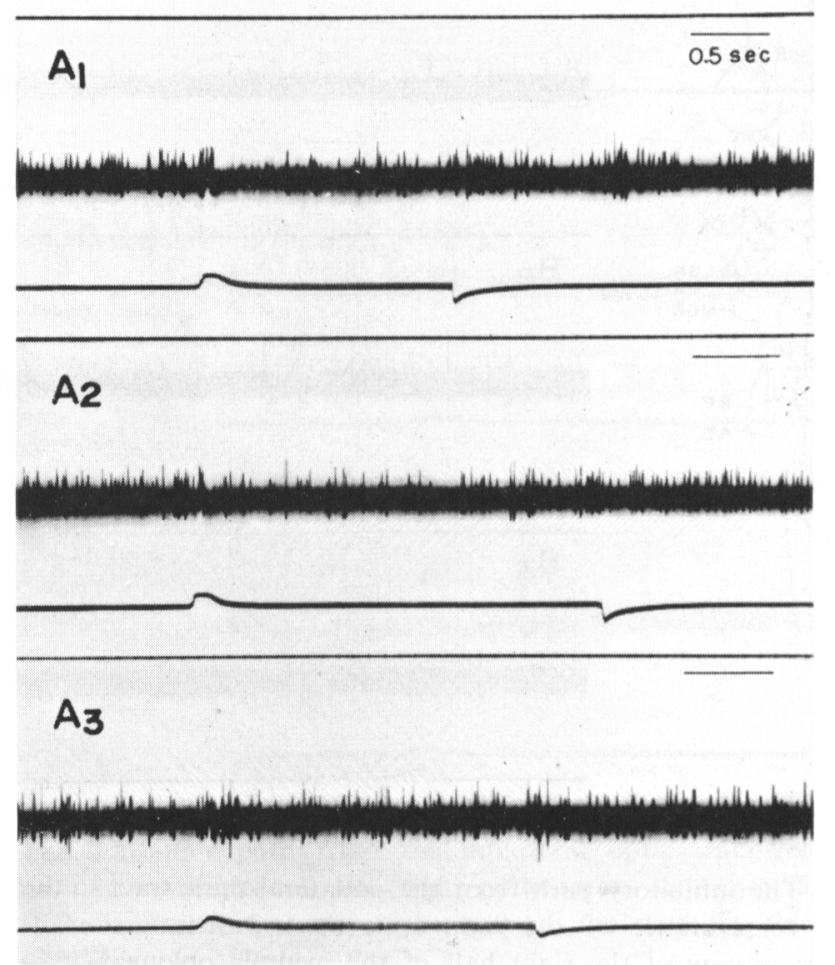

FIG. 5 A. Response in the activity of the long ciliary nerve to lighting the retina after mid-sagittal section of the midbrain.

Action potentials: led from the left long ciliary nerve. The right eye was illuminated. $\mathbf{A}_{1}$ : after severance of the left optic tract and transection of the right half of the pons, $\mathrm{A}_{2}$ : after additional mid-sagittal section of the dorsal part to the Sylvian aqueduct, $\mathrm{A}_{3}$ : after additional mid-sagittal section of the ventral part to the Sylvian aqueduct. 


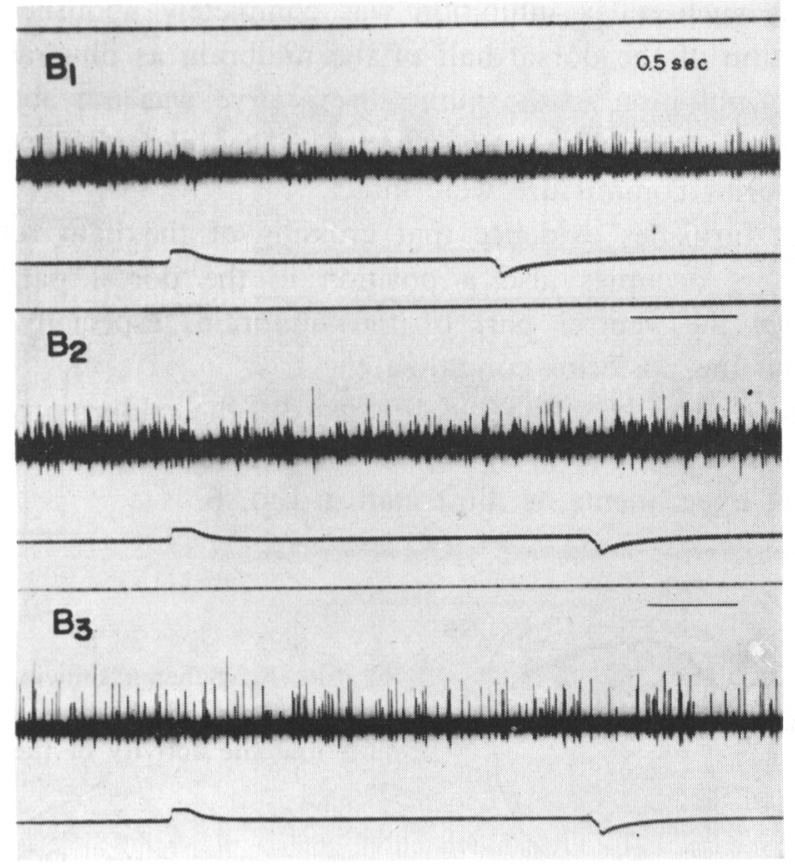

Fig. 5 B. Response in the activity of the long ciliary nerve to lighting the retina after mid-sagittal section of the midbrain.

Action potentials: led from the left long ciliary nerve. The right eye was illuminated. $\mathbf{B}_{1}$ : after severance of the left optic tract and transection of the right half of the pons, $\mathbf{B}_{2}$ : after additional mid-sagittal section of the ventral part to the Sylvian aqueduct, $\mathbf{B}_{3}$ : after additional midsagittal section of the dorsal part to the Sylvian aqueduct.

(FIG. $5 \mathrm{~A}_{1}$ ) was not abolished by mid-sagittal section of the dorsal part to the Sylvian aqueduct, although its degree diminished slightly than that before its sagittal section as shown in FIG. $5 \mathrm{~A}_{2}$. Such reflex inhibition was, however, completely abolished by subsequent mid-sagittal section of the ventral half of the midbrain as illustrated in FIG. $5 \mathrm{~A}_{3}$.

This result indicates that decussation of the light reflex path reaching the cilio-spinal centers exists in the neural structure ventral to the cerebral aqueduct. The results of the 2 nd series of experiments are described in the following.

After ascertaining the presence of the inhibitory response in the left long ciliary nerve to retinal light stimulation after cutting the left optic tract and transecting the right half of the pons (FIG. $5 \mathrm{~B}_{1}$ ), the ventral part of the midbrain was mid-sagittally sectioned with a small spatula inserted into the Sylvian aqueduct from its caudal foramen until its lesion reached the bottom of the cranial cavity. Reflex inhibition in the long ciliary nerve to lighting retina was not abolished after such an operation, although its degree slightly diminished as shown in 
FIG. $5 \mathrm{~B}_{2}$, while such reflex inhibition was completely abolished by subsequent mid-sagittal section of the dorsal half of the midbrain as illustrated in FIG. $5 \mathrm{~B}_{3}$. However, reflex inhibition in the long ciliary nerve was not abolished so far as anterior portion of connective tissues between the bilateral superior colliculi as well as the posterior commissure were intact.

This result furnishes evidence that crossing of the light reflex path to the cilio-spinal centers occupies also a position in the dorsal part to the Sylvian aqueduct besides the ventral part of the midbrain, especially in the anterior portion including the posterior commissure.

A schema concerned with the central path in the midbrain of the optic afferent impulses inhibiting the activity of the cilio-spinal centers, which was induced from the present experiments, is illustrated in FIG. 6.

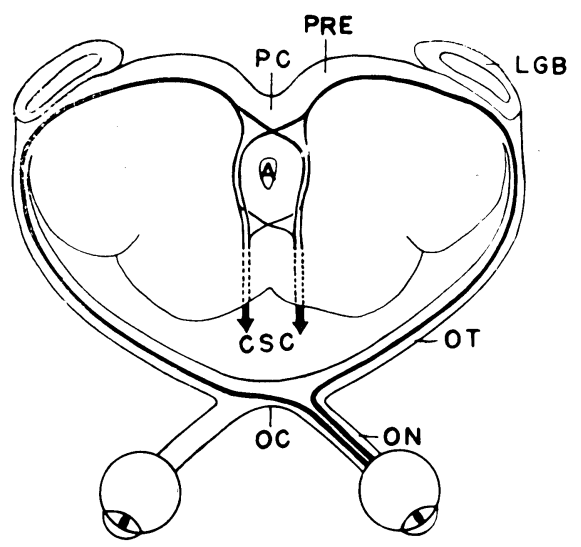

FIG. 6. Schema showing the pathway in the mid-brain of the optic afferent impulses inhibiting the activity of the cilio-spinal centers.

ON: optic nerve, OC: optic chiasma, OT: optic tract, LGB: lateral geniculate body, PRE: pretectal region, PC: posterior commissure, A: cerebral aqueduct, CSC: cilio-spinal centers.

5. Section of the medulla at the level of the acustic tubercle; In order to clarify the region of the inhibitory pathway to the cilio-spinal centers at this level, partial destruction of the unilateral medulla was performed extending progressively from the midline after interrupting the pathway descending the contralateral brain stem by the contralateral midpontine hemisection (FIG. 7 A). After each lesion the reflex response in the long ciliary nerve to lighting the retina was examined.

After confirming the presence of the inhibitory response in the left long ciliary nerve to lighting the right eye after midpontine hemisection on the right side (FIG. $7 \mathrm{C} \mathrm{a}$ ), section of the medulla to a depth of $7 \mathrm{~mm}$., and $2.5 \mathrm{~mm}$. from the midline on the left side (FIG. $7 \mathrm{~B}$ a) was performed. Such destruction had no influence on the inhibitory response in the long ciliary nerve (FIG. $7 \mathrm{C} \mathrm{b}$ ). Enlargement of the lesion $2.5 \mathrm{~mm}$. more laterally and to a depth of $4 \mathrm{~mm}$. (FIG. $7 \mathrm{~B} \mathrm{~b}$ ) did not abolish the reflex inhibition (FIG. $7 \mathrm{Cc}$ ), whereas when the section was extended to a depth of $7 \mathrm{~mm}$. from the dorsal surface (FIG. $7 \mathrm{~B} \mathrm{c}$ ) 


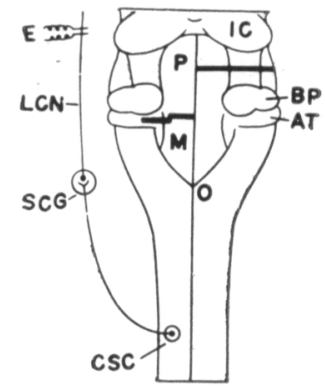

A

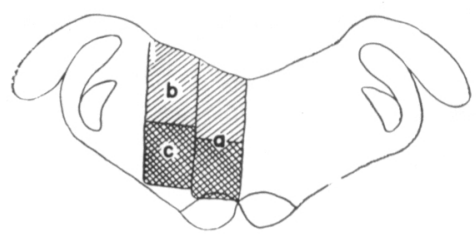

B

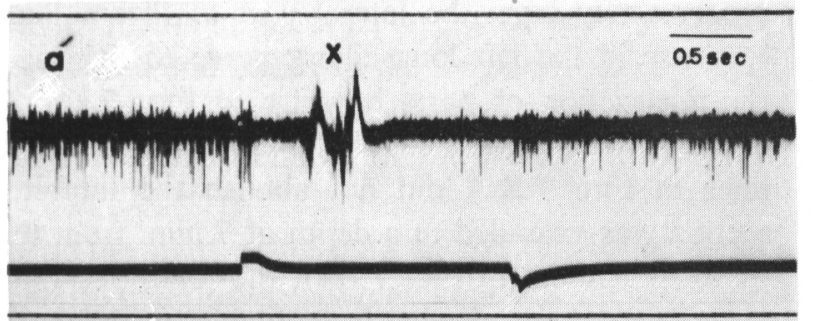

b

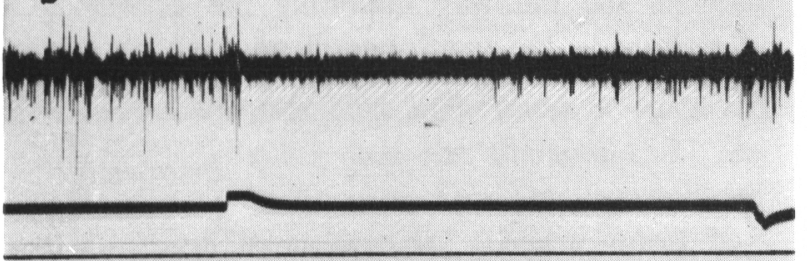

C

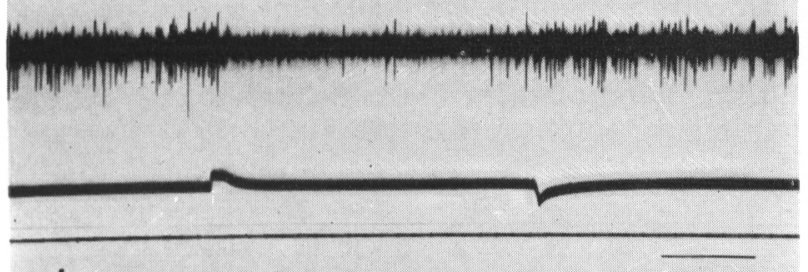

d

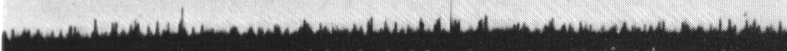

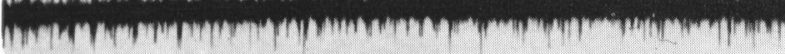

$\mathrm{C}$

FIG. 7 A. Dorsal view of the brain stem. Heavy lines indicate the place of destruction.

FIG. 7 B. Outline drawing of transverse sections through the medulla oblongata at the level of the acustic tubercle. The extent of lesions falling to abolish reflex inhibition in left long ciliary nerve to lighting the retina was indicated by oblique lines, the extent of lesions abolishing the reflex response was indicated by cross hatches.

FIG. $7 \mathrm{C}$. The reflex response in the long ciliary nerve to lighting the retina after destruction of the medulla at the level of the acustic tubercle.

Action potentials: led from the left long ciliary nerve. The right eye was illuminated. a: after transverse section of the right half of the pons, b: after additional lesion of the area in fig. $7 \mathrm{~B}$ a, c: after additional lesion of the area in fig. $7 \mathrm{~B} \mathrm{~b}, \mathrm{~d}$ : after additional lesion of the area in fig. 7 B c. $X$ in fig. a marks artifact produced by reflex contraction of the external ocular muscles.

a reflex inhibition in the left long ciliary nerve was abolished (FIG. $7 \mathrm{C} \mathrm{d}$ ).

In other instances, partial destruction of the unilateral medulla was extended 
progressively from the lateral part to the midline. In such cases, the inhibitory response in the left long ciliary nerve to lighting the retina was not abolished by the destruction of parts $b$ and $c$ in FIG. 7 B. Furthermore, enlargement of the lesion to the midline and to a depth of $4 \mathrm{~mm}$. (the area shown by the oblique lines in FIG. $7 \mathrm{Ba}$ ) did not abolish the inhibitory response, whereas when the section was extended to a depth of $7 \mathrm{~mm}$. from the dorsal surface (the area shown by cross hatches in FIG. $7 \mathrm{Ba}$ ), the reflex response was completely abolished.

From these results it is highly probable that at the level of the acustic tubercle the pathway inhibiting the activity of the cilio-spinal centers occupies a position in the ventrolateral and ventroparamedian part of the bulbar reticular formation.

\section{DISCUSSION}

From a series of experimental results described above, a diagram of the afferent pathway as illustrated in FIG. 8 is induced. The optic afferent impulses from the retina of the unilateral eyeball enter into the brain stem on each side through bilateral optic tracts after a partial crossing in the optic chiasma. From there some of them descend the homolateral midbrain, pons and medulla oblon-

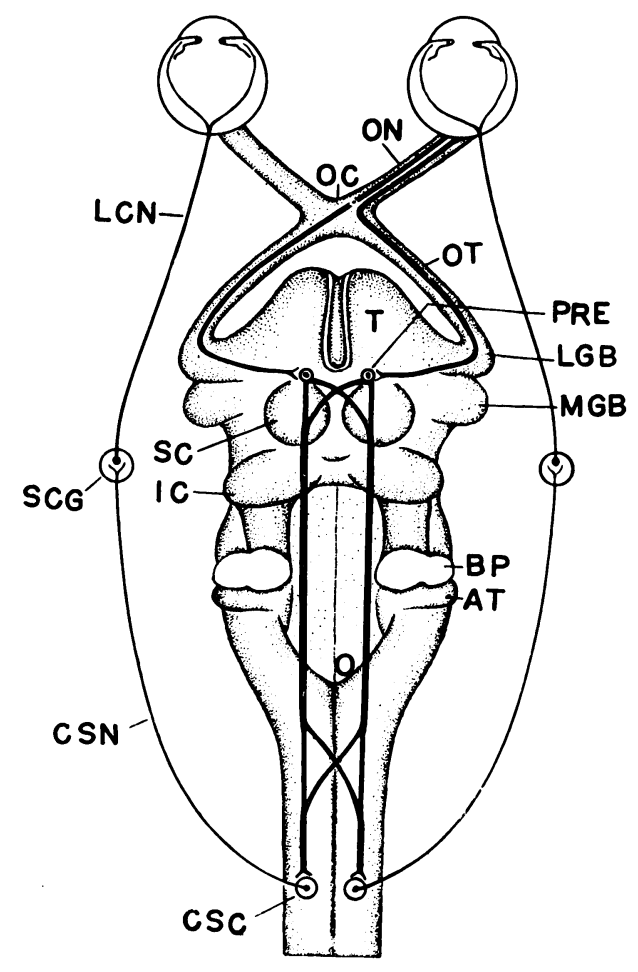

FIG. 8. Diagram of the pathway for the pupillary light reflex via the cilio-spinal centers.

The afferent pathway is in heavy lines, the efferent pathway in light lines. 
gata, whereas another runs the contralateral midbrain passing through a partial decussation in the neural structures ventral and dorsal to the Sylvian aqueduct, and descends the contralateral pons and medulla oblongata. Subsequently, each descending path reaches the bilateral cilio-spinal centers after a partial crossing in the spinal cord.

Regarding the central course of the light reflex path to the pupillo-constrictory centers, it has long been held that the optic afferent impulses for the light reflex pass from the brachium of the superior colliculus into the superior colliculi, and from there by way of the tectobulbar fibers pass to the sphincter portion of the oculomotor nucleus. A study of MAGOUn, RANSON, MAYER and others ${ }^{1-4,10,11)}$, however, has conclusively demonstrated that the pupillary light reflex is mediated extensively by the pretectal region intermediate between the thalamus and the superior colliculi of corpora quadrigemina, and that no part of the superior colliculi is concerned with this reaction. They have shown a new schema from their experimental results, according to which fibers from the unilateral pretectal region reach the bilateral oculomotor nuclei after a partial central decussation both in the posterior commissure and ventral to the central gray matter of the cerebral aqueduct. Nisida and KoIKE,6) have described recently that all of the light reflex fibers from the unilateral pretectal region run to the contralateral oculomotor nucleus after a complete crossing both in the posterior commissure and in the ventral part of the cerebral aqueduct and does not run the ipsilateral oculomotor nucleus. The course in the midbrain of the path inhibiting the cilio-spinal centers induced from the results in the present study (FIGs. 6, 8) seemingly resembles that of the path to the oculomotor nuclei represented in the diagram of MAGOUN, RANSON and MAYER, but contradicts to that of Nisida and KoIKE. In this study, a question as to either the pretectal region or the superior colliculus is the site of a synapse in the pathway inhibiting the activity of the cilio-spinal centers remains unsolved, but from the work of MAGOUN, RANSON and others ${ }^{1-4,10,11)}$ the cell station seems to situate at the pretectal region. However, in order to conclusively elucidate this problem it further requires to study the effect of lighting the retina upon the activity of the cilio-spinal centers after destruction of the superior colliculi or of the pretectal region.

\section{SUMMARY}

The central path of the light reflex via the sympathetic nerve in the cat was studied by observing reflex inhibition of the activity in the long ciliary nerve after various combined lesions of the brain stem and optic tract. From the results a possible schema was induced.

The inhibitory path from the unilateral eye to the cilio-spinal centers entered into the midbrain through the bilateral optic tracts after a partial decussation in 
the optic chiasma. From there a part of them descended the midbrain, pons and medulla oblongata on each side, while the other descended the contralateral brain stem after a partial decussation both in the posterior commissure and ventral to the Sylvian aqueduct. Furthermore, this descending path reached the bilateral cilio-spinal centers after forming the 3rd partial decussation in the spinal cord. In the medulla oblongata this inhibitory path occupied a position in the ventral reticular formation.

\section{REFERENCES}

1) Magoun, H. W. and Ranson, S. W. Arch. Ophth. 13: 791, 862, 1935.

2) Magoun, H. W., Ranson, S. W. and Mayer, L. L. Amer. J. Ophth. 18: 624, 1935.

3) Magoun, H. W. Amer. J. Physiol. 111: 91, 1935.

4) Magoun, H. W., Atlas, D., Hare, W. K. and Ranson, S. W. Brain 59: 234, 1936.

5) Nisida, I. AND KoIKe, A. Yonago Acta Med. 2: 133, 1957.

6) Nisida, I. AND KoIKe, A. Yonago Acta Med. 3: 6, 11, 1958.

7) Nisida, I., OKada, H. AND Nakano, O. Yonago Acta Med. 4: 7, 1959.

8) Nisida, I. AND OKadA, H. Jap. J. Physiol. 10:64, 1960.

9) Nisida, I., OKada, H. AND Nakano, O. Jap. J. Physiol. 10:74, 1960.

10) Ranson, S. W. and Magoun, H. W. Arch. Neurol. Psychiat. 30: 1193, 1933.

11) Scala, N. P. ANd SpIEgel, E. A. Arch. Ophth. 15: 195, 1936. 